\section{Differences in Negative $T$ Waves Between Acute Pulmonary Embolism and Acute Coronary Syndrome}

\section{To the Editor:}

Kosuge et al $^{1}$ compared the negative $\mathrm{T}$ wave (Neg T) patterns of 107 acute pulmonary embolism (APE) patients and 248 acute coronary syndrome (ACS) patients. They concluded that "the presence of Neg T in leads III and V1 and/or peak Neg T in leads V1-2 simply but accurately differentiates APE from ACS." This is an important and oft-cited article, especially in that online ECG and free online medical education resources ${ }^{2}$ that have become increasingly popular among medical professionals worldwide.

The authors report that of the 107 APE patients, 76\% had both ECG patterns (Neg T in leads III and V1 in addition to peak Neg T in V1/V2), whereas $22 \%$ had either pattern alone. Their table 3 and the ensuing discussion give the impression that either ECG pattern in isolation is a useful discriminant (both with sensitivity $87 \%$, specificity $96 \%$, positive predictive value of $89 \%$, and negative predictive value of $94 \%$ ). However, most APE patients in the study had both ECG patterns, and based on our analysis of the data reported in table $3,11 \%$ of patients with APE and $4 \%$ of patients with ACS had 1 pattern but not the other. Thus, the positive predictive value for APE of either ECG finding alone was $55 \%$ and the negative predictive value was $71 \%$. Positive likelihood ratio for either ECG finding alone was 2.75 , and negative likelihood ratio was 0.85 . As both this and an earlier study by Kosuge et $\mathrm{al}^{3}$ showed overall greater prevalence of ACS presenting with precordial Neg T waves, the appropriate conclusion is that if only 1 of the patterns is present, the ECG has not meaningfully discriminated between APE and ACS.

However, although not explicitly reported, it appears that the presence of both ECG patterns, which occurred in $76 \%$ of APE cases and apparently 0 of the ACS cases, can provide an important discriminatory function because it would have an exceedingly high positive predictive value and positive likelihood ratio. In other words, if neither pattern is present, APE is highly unlikely; if both are present, APE would be highly favored over ACS; and if either is present in isolation (Neg T in leads III and V1 or peak Neg $\mathrm{T}$ in V1/V2), the pretest probability of APE vs. ACS has not been altered to a significant degree.

\section{Disclosures}

None.

\section{References}

1. Kosuge M, Ebina T, Hibi K, Tsukahara K, Iwahashi N, Umemura $S$, et al. Differences in negative $T$ waves between acute pulmonary embolism and acute coronary syndrome. Circ J 2014; 78: $483-489$.

2. Farkas J. Two EKG patterns of pulmonary embolism which mimic MI. PULMCrit (EMCrit) 30 July 2014. https://emcrit.org/ pulmcrit/two-ekg-patterns-of-pulmonary-embolism-whichmimic-mi/ (accessed May 10, 2021).

3. Kosuge M, Ebina T, Hibi K, Tsukahara K, Iwahashi N, Gohbara M, et al. Differences in negative $\mathrm{T}$ waves among acute coronary syndrome, acute pulmonary embolism, and Takotsubo cardiomyopathy. Eur Heart J Acute Cardiovasc Care 2012; 1: $349-357$.

Phillip Rubin, MD

Paul C. Montana, MD

Department of Internal Medicine, University of Miami Miller School of Medicine/ Jackson Memorial Hospital, Miami, FL, USA

Received May 12, 2021; accepted May 13, 2021; J-STAGE Advance Publication released online June 15, 2021

Mailing address: Phillip Rubin, MD, Department of Internal Medicine, University of Miami Miller School of Medicine/Jackson Memorial Hospital, 1600 NW 12 ${ }^{\text {th }}$ Avenue, Miami, FL 33136, USA. E-mail: pxr365@med.miami.edu All rights are reserved to the Japanese Circulation Society. For permissions, please e-mail: cj@j-circ.or.jp ISSN-1346-9843 